Dário Frederico Pasche ${ }^{1}$

Eduardo Passos ${ }^{2}$

Élida Azevedo Hennington ${ }^{3}$

${ }^{1}$ Secretaria de Atenção à Saúde, Ministério da Saúde. SAF Sul, Trecho 2, Bloco F, Edifício Premium, Torre 2, Térreo, Sala 18. 70.070-600 Brasília DF.

dario.pasche@saude.gov.br ${ }^{2}$ Departamento de Psicologia, Universidade Federal Fluminense (UFF)

${ }^{3}$ Instituto de Pesquisa Clínica Evandro Chagas, Fundação Oswaldo Cruz

\section{Cinco anos da Política Nacional de Humanização: trajetória de uma política pública}

\author{
Five years of the National Policy of Humanization: \\ the trajectory of a public policy
}


A humanização da gestão e da atenção como política pública do SUS

A Política Nacional de Humanização do Sistema Único de Saúde (PNH) foi criada em 2003 pelo Ministério da Saúde e pactuada na Comissão Intergestores Tripartite e Conselho Nacional de Saúde ${ }^{1}$. A PNH é, portanto, uma política do SUS. Também chamada de HumanizaSUS, a PNH, emerge da convergência de três objetivos centrais: (1) enfrentar desafios enunciados pela sociedade brasileira quanto à qualidade e à dignidade no cuidado em saúde; (2) redesenhar e articular iniciativas de humanização do SUS e (3) enfrentar problemas no campo da organização e da gestão do trabalho em saúde que têm produzido reflexos desfavoráveis tanto na produção de saúde como na vida dos trabalhadores².

Arouca já defendia na $11^{\text {a }}$ Conferência Nacional de Saúde ${ }^{3}$ que a reforma sanitária era muito mais do que um processo meramente tecnoburocrático ou gerencial na história da saúde pública brasileira; tratava-se de um marco na direção do aprimoramento de nossa experiência civilizatória. Em outras palavras: a construção do SUS teria como uma de suas consequências o aperfeiçoamento de nossa própria experiência como sociedade, então mais justa e solidária a partir da defesa de valores como democracia direta, controle social, universalização de direitos e humanização do cuidado. E ampliando a visão de saúde para além da assistência com a incorporação da promoção e prevenção e reconhecendo o cidadão não como simples cliente ou usuário, mas como sujeito. O aprimoramento do padrão de civilidade seria decorrência de um novo modo de ação na esfera pública, de um modo de fazer política pautada pela inclusão dos sujeitos, negociação orientada por princípios éticos e produção de um plano comum tomando por referência as diferenças entre sujeitos, movimentos sociais e o Estado. Movimento este muito diferente da tradição privatista e de exclusão do Estado brasileiro cujos efeitos levaram à construção de um dos sistemas de saúde mais injustos do planeta.

Negri ${ }^{4}$ sobre o Poder constituinte argumenta que a democracia é uma "essência insolúvel": sem se resolver mantém-se, portanto, como obra aberta. Uma consequência da forma mais pactuada e concertada de produção de políticas públicas é que o SUS se apresenta assim, como uma "obra aberta", pois resulta de consensos mínimos e provisórios, atualizados no processo de cotejamento entre interesses de sujeitos em espaços públicos de gestão. Assim, o SUS seria uma eterna "reforma incompleta", tomando a expressão de Gers- $\operatorname{chman}^{5}$, pois sua forma de gestão implicaria em mudanças que jamais cessariam, assumindo uma plasticidade decorrente do jogo de interesses que atravessam a sociedade brasileira.

A Política de Humanização nutre-se e reinveste na tradição do SUS, de um modo de fazer política. Reinveste na reforma: o sentido de repetição que o prefixo impõe a esta palavra ganha aqui um valor particular. Reformar para o ideário do movimento sanitário brasileiro não pode ser entendido como revisionismo que abranda as radicalidades e contemporiza os conflitos. Reformar significa rever as formas instituídas no campo das práticas de saúde, colocando em análise as instituições para fazer valer o processo de institucionalização que deve permanecer vivo e ativo. Reformar para formar de novo, para revolver o que já está demasiadamente estável e cristalizado.

Diante dos impasses éticos, políticos, financeiros e de organização do sistema de saúde presentes no cenário brasileiro, impõe-se o debate sobre a humanização e o questionamento do modelo tecnoassistencial e a qualidade da atenção à saúde no que tange à disponibilização de tecnologias, recursos e saberes aos sujeitos e às populações visando mitigar seu sofrimento ${ }^{6}$. Neste sentido, apostar na humanização da atenção e gestão do SUS retoma a agenda da reforma sanitária ao chamar atenção para a necessidade de problematizar os modos de fazer presentes nas práticas de saúde desenvolvidas pelos trabalhadores e equipes no cotidiano.

\section{A micropolítica e a microgestão como espaços estratégicos da produção de mudanças na saúde}

Antes de tudo é necessário ressaltar que a PNH tomou como desafios os problemas e dificuldades que ainda permanecem no SUS em sua trajetória de mais de 20 anos $^{7}$. Os impasses vividos e enfrentamentos a serem feitos para a sustentação do projeto brasileiro por uma política pública de saúde colocam para a militância do SUS a necessidade da manutenção daquele movimento constituinte que ensejou, na constituição de 1988, a formulação do direito cidadão à saúde.

A PNH, ao mesmo tempo em que reconhece os desafios do sistema público de saúde, parte e aposta em um "SUS que dá certo", experimentado por uma vasta gama de serviços, equipes, trabalhadores e usuários. Estas experiências estão presentes em todo território brasileiro e informam sobre possibilidades reais e concretas de superação desses desafios. Assim, a humaniza- 
ção do sistema se apresenta não só como emergência de novas propostas, mas também como estratégia de valorização da experimentação do SUS que já se dá no dia-a-dia das práticas de gestão e de atenção à saúde, constituindo-se como instrumento de reencantamento do concreto ${ }^{8}$. A valorização do cotidiano como elemento para a formulação de políticas públicas é também uma inovação na medida em que as políticas de saúde se originam em geral do aparato burocrático do Estado, tão afeito à normatização e à prescrição.

Tomar o concreto das práticas de saúde sem demonizá-las nem idealizá-las requer se colocar ao lado da experiência dos trabalhadores e usuários do SUS. Investir no novo, apostando na criatividade e colocar-se ao lado da experiência sem falar sobre ela nem falar por ela, mas falar com ela. Estar ao lado para fomentar lateralidade, para criar rodas de comunicação $0^{9}$ onde os saberes e os poderes possam circular por entre os sujeitos implicados no processo de produção de saúde. É preciso alterar o padrão organizacional e de gestão do trabalho em saúde que verticaliza e hierarquiza os discursos ou os homogeneíza na horizontalidade corporativa dificultando a comunicação.

Com a PNH o tema da participação em saúde igualmente assume novos contornos, ampliando-se na direção da inclusão protagonista e corresponsável dos diferentes sujeitos implicados no processo de produção de saúde. Para além do controle social exercido nos espaços instituídos da participação, é condição prioritária para a missão pública do SUS a criação de uma responsabilidade sanitária coletiva, isto é, a produção de um sujeito coletivo, desindividualizado e não necessariamente institucionalizado, que faz de sua ação cotidiana e local - seja o trabalho formal dos profissionais de saúde, seja o trabalho de cuidado de si dos usuários e sua rede sociofamiliar - uma forma de engajamento no movimento de mudança dos modos de cuidar e de gerir.

As mudanças no SUS não dependem apenas de definições estruturais como o financiamento e o pacto sanitário federativo que redistribui e redefine recursos e responsabilidades na saúde, entre outras. Em que pese a influência e a força desses elementos é necessário apontar na direção da valorização e problematização da experiência no cotidiano do trabalho em saúde, que tem potência de transformação, portanto de reinvenção dos serviços e práticas.

A saúde é direito de todos, mas não pode ser somente dever do Estado. A grande pretensão brasileira por uma política pública de saúde que seja universal, equânime e integral exige uma distribuição da responsabilidade pela garantia do direito cidadão. Desse modo, o SUS se faz em um duplo e complementar movimento político: na macropolítica do jogo de forças entre as instâncias gestoras do SUS e os movimentos organizados no campo da saúde e na micropolítica do jogo das forças que, aquém e além das formas individuais e sociais, engendram o mundo e os sujeitos - processos de produção de si e de produção de mundo - tudo isso em meio à perversão do capitalismo ${ }^{10}$. O desafio é o de manter este duplo ativismo político, macro e micro, entendendo que o SUS se faz pelos acordos molares e movimentos moleculares $^{11}$ que evidenciam a indissociabilidade entre produção de saúde, produção de subjetividade e produção de mundo, considerando-se que os planos macro e micropolítico se codeterminam e se influenciam mutuamente.

Assim sendo, é necessário compor agendas políticas no SUS que não tomem como separados esses planos, mas que os compreenda em sua mútua interferência, pondo em questão as relações de poder construídas entre usuários/rede social e trabalhador/equipe de saúde. Este cenário coloca para as políticas de saúde a importância de propor - formular e ofertar - dispositivos que alterem modos de fazer no cotidiano do trabalho. Ou seja, é estratégico que além de ofertas extensivas se invista e se ocupe do trabalho e da ação de cada uma das equipes de saúde, sem o que a política pública de saúde perde em potência de transformação de realidades. Entenda-se atividade extensiva como a realização e participação em eventos, produção de materiais de divulgação, desenvolvimento de tecnologias de inteligência coletiva (banco de experiências, site da $\mathrm{PNH}$, no Ministério da Saúde, Rede HumanizaSUS < http://redehumanizasus.net/>), etc. A estratégia extensiva orienta as práticas de saúde a partir de ações massivas e de imediata abrangência de maiores contingentes da população; já a estratégia intensiva visa alcançar efeitos globais a partir da reverberação de ações locais.

\section{Apostas da PNH para enfrentamento dos desafios de reorientação das práticas, qualificação do cuidado e aprimoramento da gestão do trabalho em saúde}

A PNH não inaugura o tema da humanização no sistema de saúde brasileiro, mas muda seu sentido e estratégias. Até 2003 havia uma série de iniciativas de humanização que tinham por características a dinâmica de programas, a baixa transversalidade entre os programas e setores do MS e a imprecisão conceitual sobre o objeto humanização da saúde ${ }^{12-14}$. 
Com isto não se quer negar a pertinência e a importância dessas iniciativas, ao contrário. Sem elas não haveria a formulação de uma Política de Humanização. Todavia, a construção de "programas de humanização" (do parto, da saúde da criança, da assistência hospitalar, etc.) estava na contramão da tendência de organização do SUS, que caminha cada vez mais na direção da corresponsabilização dos agentes sanitários na formulação e na implementação de práticas de saúde. Programas têm por lógica a predeterminação de um modo homogêneo de fazer, que desdenha e não se ocupa da capacidade criativa da ponta do sistema, "da periferia", lá onde as práticas concretas delineiam modos de fazer ${ }^{15}$. Além disso, sua forma de acompanhamento se dá pelo controle, em geral, dos recursos previstos em incentivos, valorizando o cumprimento de metas e resultados e desprezando os elementos de processo pelos quais as mudanças se tornam possíveis e sustentáveis, ou seja, os elementos que atuam em sua dinâmica de produção. Por fim, programas têm por natureza a baixa transversalidade, sendo pouco potentes para a ampliação da comunicação entre diferentes áreas e projetos e reorientação das práticas, tendendo a manter certo modo de operar que não aciona redes, pois delimita sua esfera de ação em campos circunscritos a determinadas áreas, setores, atores e objetos de ação.

A PNH apresenta-se não mais como um programa, mas como uma política para se reinventar modos de gerir e modos de cuidar, tomando por diretrizes o acolhimento, a ampliação da clínica, a gestão democrática, a valorização do trabalhador e a garantia dos direitos dos usuários. Estas diretrizes se apóiam em três princípios: a ampliação da transversalidade ou aumento do grau de abertura comunicacional intra e intergrupos, favorecendo a capacidade de interferência mútua entre sujeitos e a sua capacidade de deslocamento subjetivo; a inseparabilidade entre gestão e atenção e, finalmente, a aposta no protagonismo dos sujeitos em coletivos. A humanização se singulariza na experiência de cada serviço e equipe e, assim, não haveria uma só experiência de humanização igual à outra, senão naquilo que tomam por referência, ou seja, método e diretrizes ético-políticas, que ganham forma e expressão na singularidade da experiência.

Esses princípios acionam o método da $\mathrm{PNH}$, definido como inclusão de sujeitos e coletivos, seja na gestão (dos serviços e das práticas de atenção à saúde) seja na corresponsabilização no cuidado de si e dos outros e nos processos de trabalho. Assim, incluir toma um sentido ético-político, pois não se quer incluir para manipular, sub- jugar, nem para docilizar corpos e relações ${ }^{16}$, mas partindo das diferenças e da perturbação que elas produzem (entre interesses e necessidades de trabalhadores, gestores e usuários), construir um plano comum que não despreza os sujeitos e suas experiências concretas de vida, nem se centraliza em alguma polaridade, mas se faz como síntese provisória, como acordo que permite agir em prol de uma causa comum, do bem comum.

De outra parte, a Política de Humanização toma por humano não uma referência idealizada do "bom homem", senão o homem real encarnado em práticas sociais concretas ${ }^{12-14}$. Isto informa que a humanização da saúde não se faz por uma atitude de prescrição moral para lidar com a complexidade e o paradoxo humanos, numa ação de cima para baixo, de maneira extrínseca ou heteronômica, de fora do sujeito e de suas relações. Não se deseja a "caça" àquilo que poderia ser adjetivado de "mau no humano", como a intolerância, os narcisismos, o egoísmo, o desejo de captura do outro, etc., características que também se constroem e comparecem na experiência humana como efeito de condições sócio-históricas dadas. A modificação dos modos de gerir e de cuidar não é propriamente uma problemática das consciências, não pode ser tomada como índice do voluntarismo ou da decisão de foro íntimo de trabalhadores e usuários de saúde, mas de experimentação, no espaço do trabalho, de dispositivos com potência para a promoção de reposicionamentos subjetivos e que possam ampliar a capacidade das pessoas de se compreenderem como fenômenos complexos e contraditórios.

A rede de forças multivetoriais nas relações entre trabalhador-usuário necessita ser cartografada indicando suas linhas de composição: linhas duras ou flexíveis, mais ou menos instituídas, mais ou menos refratárias a mudanças ${ }^{17}$. É necessário que esta rede seja analisada e a PNH sugere a construção e a ativação de espaços coletivos, espaços públicos - e em alguma medida protegidos - para a análise da experiência singular de ser trabalhador da saúde.

Esta constatação fez emergir um traço singular da PNH que é se apresentar como uma política transversal ${ }^{2}$. Qualificar de transversal uma política de saúde significa atribuir às suas práticas um caráter de comunicação e de comunalidade. $O$ conceito de transversalidade deve ser entendido aqui como um terceiro eixo que altera o padrão tradicional de comunicação organizado a partir dos eixos vertical e horizontal nas instituições de saúde: eixo vertical da hierarquização dos diferentes e o eixo horizontal que homogeneíza a comunicação na corporação dos iguais. Este con- 
ceito proposto por Guattari ${ }^{18}$ no início da década de 60 tem neste seu sentido comunicacional uma aposta na expressão de uma experiência comum que pode dar unidade ao engajamento dos diferentes sujeitos em um projeto institucional.

Além da necessidade de reorientação das práticas, um segundo elemento que influenciou decisivamente na construção da política de humanização foi (e tem sido) a permanente denúncia da "precarização no cuidado" - denúncia amplificada pela mídia que em geral destaca a "desumanização" como uma das principais expressões do SUS. Este qualificativo não está dissociado da avaliação positiva que usuários expressam do SUS, captada em pesquisas de âmbito nacional ${ }^{19,20}$. O povo brasileiro aponta que o SUS é uma conquista da sociedade, sobretudo porque reconhece o direito à saúde e igualmente a importância e o impacto das modificações no sistema e serviços de saúde e na configuração das redes assistenciais, como, por exemplo, a forte presença da estratégia da saúde da família, que produz e amplia vínculos terapêuticos. Todavia, se aponta com força e clareza para dois aspectos bastante negativos: a dificuldade da definição de responsabilidades no processo de cuidado (indefinição de quem cuida de quem) e a não garantia de cuidado longitudinal e nos diferentes níveis de atenção.

Estes dois aspectos sintetizam o que tem caráter de anti-humanização: baixa responsabilização e descontinuidade nos tratamentos que, por sua vez, expressam a própria organização do sistema (precariedade da rede básica e de funcionamento do sistema de referência e contrarreferência em muitos locais) e a qualidade das relações clínicas refletida no descaso, no descuido, no cuidado burocrático e indiferente a que é submetido um vasto contingente de brasileiros. No entanto, é preciso clarear esta crítica. De quem ou de que se fala quando se identifica clínica ou práticas degradadas porque supostamente desumanas? Trata-se da desumanidade de certos homens que cumprem mal suas tarefas profissionais?

Se assim se formula o problema, coloca-se a embaraçosa tarefa de "humanizar humanos" como se alguns destes homens fossem menos humanos. Neste caso, haveria comprometimento com a insustentável tese de uma humanidade gradativa ou da existência de graus de humanidade. Certamente, é mais prudente supor que as práticas de saúde condenáveis são menos determinações de certos homens do que efeito de condições precarizadas de trabalho e de modelos de atenção e de gestão descompromissados, obsoletos e incompatíveis com a missão do SUS. É neste sentido que se quer dar uma definição po- sitiva - e não mais negativa - à humanização da saúde: humanizar não como o contrário do desumano ou inumano, mas humanizar como a construção das condições de emergência de trabalhadores e usuários protagonistas, autônomos e corresponsáveis.

Já de algum tempo tem se apontado que o trabalho em saúde ocorre substantivamente por meio do encontro ${ }^{21}$, portanto o "produto da saúde" emerge das relações que se estabelecem entre os sujeitos. Ou seja, a produção de saúde se dá mediante processos intercessores ${ }^{22}$, derivando inexoravelmente do trabalho vivo em ato ${ }^{23}$. Partindo deste pressuposto, é necessário que se restabeleçam linhas de conexão e de produção de desvio do instituído na relação usuário-trabalhador, que sejam potentes para a construção de contratos terapêuticos como recursos e qualificação da vida. Na mesma medida, este movimento deve fomentar a ampliação dos sentidos do trabalho qualificando-o como uma importante força ontogenética, de produção de sujeitos mais livres e autônomos ${ }^{24}$.

A PNH toma a Clínica Ampliada ${ }^{25}$ como uma de suas diretrizes, com a construção de processos dialógicos que permitam dar passagem aos interesses, necessidades e desejos dos sujeitos que habitam esta relação, sem o que não é possível a construção de processos de corresponsabilização. A tarefa substantiva que a $\mathrm{PNH}$ põe como desafio é a reconstrução das relações clínicas (e da saúde coletiva, por suposto), o que exige alterações na dinâmica de gestão do trabalho. Isto se deve ao fato de que a mudança das relações trabalhador da saúde-usuário não pode ser compreendida como decorrente apenas da vontade particular dos sujeitos, senão como resultado da afirmação do conceito de subjetividade como efeito emergente de uma complexa rede de forças biológicas, sociais, culturais e políticas, da definição de produção de saúde como construção de autonomia com o outro para o cuidado de si e da ampliação do conceito de saúde, que estende a intervenção do campo sanitário para além dos conhecimentos e das práticas médicas, requisitando ação transdisciplinar e intersetorial ${ }^{26}$.

Por fim, o terceiro elemento que atua na construção da PNH é a presença de inúmeros problemas no campo da gestão do trabalho em saúde. A tarefa de construção do SUS não pode deixar de considerar que além de produzir mais e melhor saúde, o trabalho e as organizações de saúde também produzem subjetividade ${ }^{27}$. Assim, o trabalho em saúde tem pelo menos uma dupla tarefa: produzir saúde e produzir subjetividade. A produção de subjetividade pelo trabalho em 
saúde convoca à discussão o tema da gestão dos processos de trabalho e as condições concretas e efetivas para a sua realização ${ }^{28,29}$.

A tradição hegemônica de gestão do trabalho tomou o trabalhador como insumo e sua denominação de "recurso humano" não é casualidade. Assim, o trabalho é destinado à produção de bens e de serviços para os outros e, nesta medida, sua realização se dá mediante o controle de quem o realiza. Esta concepção produziu e aprofundou uma visão negativa do trabalho, o que no campo da saúde produz uma série de efeitos, entre os quais a perda de efetividade das práticas clínicas e de saúde pública e a desresponsabilização.

A própria Organização Mundial da Saúde ${ }^{30}$ tomou a questão de "cuidar do cuidador" como tema estratégico da agenda da saúde na primeira década do novo milênio. Mas o que seria cuidar e valorizar o trabalhador? De uma forma breve pode-se apontar para duas direções. Uma delas toma a questão dos processos de trabalho, que abrange desde a remuneração do trabalhador, formas de vínculo empregatício, passando pelo tema da ambiência, até o acesso a tecnologias de cuidado que favoreçam a produção de saúde pelo trabalhador como recurso para a dignificação de seu trabalho e ampliação de seu valor de uso. Nesta direção cabem ainda os temas da saúde e segurança, incluindo, por exemplo, as situações de vulnerabilidade aos quais os trabalhadores estão submetidos no mundo do trabalho.

Todavia, esta direção não esgota a pauta de ofertas da $\mathrm{PNH}$, que aponta para a necessidade de se democratizar as relações de poder nas organizações de saúde. É provável que uma considerável quota de problemas de saúde que atingem os trabalhadores como acidentes de trabalho, uso abusivo de álcool e drogas, depressão e diversas outras doenças e agravos esteja relacionada à gestão e organização do trabalho.

Uma das formas de ampliar o sentido do trabalho e a vontade de fazer, a implicação e a responsabilização dos sujeitos é através da efetiva participação na gestão dos processos de trabalho, portanto a inclusão das pessoas, de fato, nos processos de tomada de decisão nas organizações. De modo geral, os trabalhadores se sujeitam e sofrem a gestão e pouco participam dela. A PNH toma a cogestão e a gestão compartilhada como uma diretriz, apostando na democratização das relações de poder como um valor e como um requisito para a ampliação da corresponsabilização dos trabalhadores ${ }^{31}$.

É necessário, contudo, acrescentar que a democratização só se radicaliza como uma prática concreta de inclusão dos diferentes sujeitos, quan- do não se restringe aos espaços formais de participação, na prática, nem sempre democráticos. É só através da alteração da complexa rede de relações de poder das instituições que a democratização das práticas de produção de saúde pode se realizar não apenas como um lema. Os arranjos coletivos de cogestão (a exemplo das Câmaras Técnicas, Grupos de Trabalho de Humanização, Ouvidorias, Colegiado Gestor e outros) são dispositivos promotores da participação dos sujeitos no planejamento, execução e avaliação das práticas de saúde, sendo estratégicos na medida em que permitem disparar processos de mudança, estes sim capazes de alterar a dinâmica comunicacional e de concentração e circulação de poder nas organizações de saúde. A participação dos trabalhadores não se restringe apenas à esfera direta de sua ação no campo do cuidado, senão em outros espaços que determinam e condicionam o trabalho, observando-se com clareza o princípio da inseparabilidade entre gestão e clínica/cuidado.

A PNH não se diferenciaria de outras políticas se fosse definida apenas pelo seu atual cardápio de ofertas. A PNH é, antes de tudo, uma oferta metodológica e informa sobre um modo de fazer que se realiza pelo Método da Tríplice Inclusão $^{2}$ : dos diferentes sujeitos envolvidos nos processos de produção de saúde (trabalhadores da ponta, trabalhadores em cargo de gestão e usuários); da perturbação que esta inclusão produz na gestão e nos processos de cuidar; e por fim, a inclusão dos coletivos que se formam e consolidam a partir das duas inclusões anteriores, como um modo de incluir novos parceiros e multiplicar os agentes de contágio da política.

Assim, valorizar os sujeitos é incluí-los nos diagnósticos institucionais e na construção de estratégias de superação dos problemas. Incluir o trabalhador é retirá-lo do lugar e posição que a gestão tradicional o colocou: como incapaz, a ponto de ter que ser gerido, e como indolente e perigoso, a ponto de ser controlado. Cuidar do cuidador não se faz tampouco por medidas piedosas e paternalistas. Cuidar é produzir com o outro possibilidades de alteração dos processos que originam sofrimento/problemas de saúde, então "sinais e sintomas" de condições e modos de gestão e de organização do trabalho.

\section{A Política Nacional de Humanização: movimentos, limites e perspectivas}

A PNH tem sido reconhecida como uma política que afirma sua dimensão pública, identificada com ideais ético-políticos do campo da saú- 
de, como a universalidade e a equidade no acesso e o direito ao cuidado, considerando-se o sentido integral para o conceito de saúde. Tem servido como uma referência para se problematizar processos de trabalho em saúde e interrogar determinados fenômenos presentes no cotidiano da atenção como as filas desnecessárias, a descontinuidade dos tratamentos, a indiferença frente à dor e ao sofrimento, a falta de recursos, o descaso diante de situações dramáticas da vida, que passam cada vez mais a serem confrontados com pressupostos éticos como o direito à saúde, o direito à informação, o direito à inclusão de redes sociais nos processos terapêuticos, o direito a ter tratamento respeitoso e digno.

Os primeiros anos da PNH foram destinados à formulação e consolidação da humanização como política pública, com sustentação teórico-metodológica, e à sensibilização e mobilização dos serviços de saúde, trabalhadores, gestores e usuários, fazendo conhecer a PNH por meio, entre outros, de atividades extensivas.

A partir de 2006, com o investimento da $\mathrm{PNH}$ em processos de formação de apoiadores institucionais, estas estratégias extensivas foram articuladas de forma mais sistematizada com atividades intensivas, como a realização de apoio a serviços e equipes de saúde (serviços hospitalares, de atenção básica, equipes gestoras, dentre outros). A função de apoio resulta da ação de sujeitos que "atravessam" o processo de trabalho de coletivos, ajudando-os nas tarefas de qualificar suas ofertas clínicas e de asúde pública, de um lado, e ampliar o grau de grupalidade, de outro. Outra ação importante foi a realização de processos e atividades de formação ${ }^{32}$. Formação para a PNH é inseparável de intervenção e por isso os cursos promovidos são estratégias, ao mesmo tempo, de capilarização da política e de experimentação de diretrizes, método e dispositivos da PNH em toda rede do SUS.

Dentre as perspectivas, uma tarefa que se coloca é ampliar a institucionalidade da PNH como política do SUS, o que exige organização sistemática da PNH junto às Secretarias Estaduais e Municipais de Saúde. Apoiar e fomentar a descentralização através da criação de coordenações loco-regionais da política de humanização, de Grupos de Trabalho de Humanização e de Câmaras Técnicas têm sido também uma aposta importante, pois estes espaços são estratégicos para a efetivação do HumanizaSUS.

Essa aposta, todavia, deve ser construída pari passu à autonomização da humanização como movimento politico da sociedade brasileira, ou seja, a experimentação e a sustentação do Humaniza-
SUS como política pública exige que seja estabelecido para além dos limites da máquina do Estado. Neste caso, trata-se de constrangimento que se coloca como desafio; estar no Estado mantendo-se no seu limite, ali onde a máquina é forçada a se articular com o seu exterior.

Sabemos que o SUS é política de Estado e se sustenta na máquina estatal a partir de políticas de governo. No entanto, é desafio do SUS a sua consolidação como política pública, isto é, como modo de produção de saúde encarnado na prática concreta dos trabalhadores e usuários, um modo de produção que se desvia das formas instituídas de cuidar e gerir o trabalho na saúde. Daí a necessidade do HumanizaSUS se situar no limiar da máquina de Estado, cujas idiossincrasias tendem a capturar e amortecer exatamente aquilo que permite e justifica a presença da $\mathrm{PNH}$ no SUS: sua natureza instituinte e desviante.

Assim, a Política de Humanização se apresenta como um importante marco de referência para a construção de práticas de saúde que efetivamente respeitem o cidadão em seus valores e necessidades. Todavia, é necessário que se avance e se amplie o senso de cidadania do povo brasileiro, que em muitas situações resigna-se aos maus tratos e ao desrespeito. Saúde digna é direito e compromisso do usuário e dever do Estado, que deve garantir a oferta de atenção de acordo com as necessidades de saúde da população. Mas a amplitude desta missão não pode ser alcançada sem a mobilização das forças sociais que se agenciam para além do Estado. O dever do Estado e das equipes de governo deve ser também o do fomento da autonomia dos diferentes sujeitos implicados no processo de produção de saúde, multiplicando os agentes do direito e do dever.

Uma aposta nesse sentido é que a PNH sirva como estratégia de mobilização social, mas não apenas de denúncia e de reivindicação de direitos, mas de afirmação de um modo de construção de alternativas de enfrentamento dos desafios que a saúde tem pela frente e que considera as diferenças e singularidades. Um modo de fazer que põe sujeitos em contato para se afetarem mutuamente, para produzirem acordos que nos transformem a cada dia em uma sociedade mais justa e fraterna.

\section{Colaboradores}

DF Pasche, E Passos e EA Hennington participaram igualmente de todas as etapas de elaboração do artigo. 


\section{Referências}

1. Mori ME, Oliveira OVM. Os coletivos da Política Nacional de Humanização (PNH): a cogestão em ato. Interface Comun Saúde Educ 2009; 13(Supl. 1):627-640.

2. Brasil. Ministério da Saúde (MS). Secretaria de Atenção à Saúde. Política Nacional de Humanização da Saúde. Documento Base. $4^{\text {a }}$ ed. Brasília: Ministério da Saúde (MS); 2007.

3. Brasil. Ministério da Saúde, Conselho Nacional de Saúde. $11^{\text {a }}$ Conferência Nacional de Saúde, Brasília 15 a 19 de dezembro de 2000. O Brasil falando como quer ser tratado: efetivando o SUS: acesso, qualidade e humanização na atenção à saúde com controle social [relatório final]. Brasília: Ministério da Saúde (MS); 2000.

4. Negri A. Poder constituinte. Rio de Janeiro: DP\&A; 2002.

5. Gerschman S. A democracia inconclusa: um estudo da reforma sanitária brasileira. Rio de Janeiro: Fiocruz; 1995.

6. Deslandes S, Ayres JRCM. Humanização e cuidado em saúde [editorial]. Cien Saude Colet 2005; 10(3): 510.

7. Pasche DF. Política Nacional de Humanização como aposta na produção coletiva de mudanças nos modos de gerir e cuidar. Interface Comun Saude Educ 2009; 13(Supl. 1):701-708.

8. Varela F. O reencantamento do concreto. In: Pelbart PP, Costa R, organizadores. Cadernos de Subjetividade (reencantamento do concreto). São Paulo: Hucitec; 2003. p.71-86.

9. Campos GWS. Um método para análise e co-gestão de coletivos - a construção do sujeito, a produção de valor de uso e a democracia em instituições: o método da roda. São Paulo: Hucitec; 2000.

10. Neves CAB, Massaro A. Biopolítica, produção de saúde e um outro humanismo. Interface Comun Saúde Educ 2009; 13(Supl. 1):503-514.

11. Guattari F. Revolução Molecular: pulsações políticas do desejo. São Paulo: Brasiliense; 1987.

12. Barros RB, Passos E. A humanização como dimensão pública das políticas de saúde. Cien Saude Colet 2005; 10(3):561-571.

13. Barros RB, Passos E. Humanização na saúde: um novo modismo? Interface Comun Saúde Educ 2005; 9(17):389-394.

14. Souza LAP, Mendes VLF. O conceito de humanização na Política Nacional de Humanização (PNH). Interface 2009; 13(Supl. 1):681-688.

15. Testa M. Pensar em Saúde. Porto Alegre: Artes Médicas; 1992.

16. Foucault M. Vigiar e punir. Petrópolis: Vozes; 1977.

17. Passos E, Kastrup V, Escóssia L, organizadores. Pistas do método da cartografia: pesquisa-intervenção e produção de subjetividade. Porto Alegre: Sulina; 2009.

18. Guatari F. Transversalidade. In: Guatari F, organizador. Revolução molecular: pulsações políticas do desejo. São Paulo: Brasiliense; 1981. p. 88-105.
19. Szwarcwald CL, Viacava F, Vasconcellos MTL, Leal MC, Azevedo LO, Queiroz RSB, Carvalho MF, Fonseca MG, Frias PG, Gama SG, Souza Júnior PRB, Lansky S, Luhm KR, Mazzei MC, Ribeiro MCSA, Santos S, Souza WV, Theme M. Pesquisa Mundial de Saúde 2003: O Brasil em números. Radis/Fiocruz 2004; 1(23):14-33.

20. Brasil. Conselho Nacional de Secretários de Saúde. A saúde na opinião dos brasileiros. Brasília: CONASS 2003.

21. Teixeira RR. O acolhimento num serviço de saúde entendido como uma rede de conversações. In: Pinheiro R, Mattos RA, organizadores. Construção da integralidade: cotidiano, saberes e práticas em saúde. Rio de Janeiro: IMS, UERJ, Abrasco; 2003. p. 89-111.

22. Deleuze, G. Os intercessores. In: Deleuze. Conversações. Rio de Janeiro: Editora 34; 1992. p. 151-168.

23. Merhy EE. Saúde: cartografia do trabalho vivo. São Paulo: Hucitec; 2002.

24. Antunes R. Os sentidos do trabalho: ensaio sobre a afirmação e a negação do trabalho. $2^{a}$ ed. São Paulo: Boitempo; 2000.

25. Campos GWS. Saúde Paideia. São Paulo: Hucitec; 2003.

26. Passos E, Benevides R. A construção do plano da clínica e o conceito de transdisciplinaridade. Psic teor e pesq 2000; 16(1):71-79.

27. Pasche DF. Gestão e subjetividade em saúde: elementos para uma reforma da saúde. In: Pasche DF, Cruz I, organizadores. A saúde coletiva: diálogos contemporâneos. Ijuí: Unijuí; 2005. [Coleção saúde coletiva].

28. Hennington EA. Gestão dos processos de trabalho e humanização em saúde: reflexões a partir da ergologia. Rev Saude Publica 2008; 42(3):555-561.

29. Santos Filho SB, Barros MEB de, Gomes RS. A Política Nacional de Humanização como política que se faz no processo de trabalho em saúde. Botucatu: Interface; 2009.

30. Organização Mundial da Saúde (OMS). Relatório Mundial da Saúde 2006: Trabalhando juntos pela saúde. Genebra: Organização Mundial da Saúde; 2006.

31. Brasil. Ministério da Saúde (MS). Secretaria de Atenção à Saúde. Política Nacional de Humanização da Saúde. Gestão participativa e cogestão. Brasília: Ministério da Saúde (MS); 2009.

32. Heckert AL, Neves CAB. Modos de formar e modos de intervir: de quando a formação se faz potência de produção de coletivo. In: Pinheiro R, Barros MEB, Mattos RA, organizadores. Trabalho em equipe sob o eixo da integralidade: valores, saberes e práticas. Rio de Janeiro: IMS, UERJ, CEPESC, Abrasco; 2007.

Artigo apresentado em 04/03/2010

Aprovado em 17/07/2010

Versão final apresentada em 29/07/2010 